\title{
Inflatable Penile Prosthesis Insertion in Men with Severe Intracorporal Fibrosis
}

\author{
Bruce B. Garber Caitlin Lim \\ Hahnemann University Hospital, Drexel University College of Medicine, Philadelphia, Pa., USA
}

\section{Key Words}

Erectile dysfunction $\cdot$ Penile erection

\begin{abstract}
Objectives: To retrospectively review a series of men who underwent attempted inflatable penile prosthesis (IPP) insertion into severely scarred corpora, and to analyze the surgical techniques and instruments that contributed to a successful outcome. Patients and Methods: All IPP procedures done by a high-volume prosthetic surgeon during a 5 -year period were retrospectively reviewed. Fourteen patients with severe intracorporal fibrosis underwent 15 attempted IPP insertion procedures, and are the subject of this review. Results: A standardized surgical approach was employed for all patients. Thirteen of the 15 procedures were successful (i.e., an IPP was inserted, with satisfactory cylinder position). One procedure failed due to corporal obliteration. One patient underwent an initial failed attempt, but was successfully implanted 10 months later. Two of the 14 patients (14\%) developed peri-prosthetic infection and were explanted. Conclusion: IPP insertion into scarred corpora is difficult and occasionally impossible. We have developed a standardized surgical approach for these cases, using limited corporal excavation, followed by the use of sequential Uramix and then Carrion-Rossello cavernotomes, that we feel has improved our chance of a successful implant. However, due to the rarity of these cases, it is not possible to make definitive statements concerning the optimal surgical technique.
\end{abstract}

Copyright $\odot 2016$ S. Karger AG, Basel
Cㄱ 2016 S. Karger AG, Basel

\section{KARGER}

Fax +4161306 1234

E-Mail karger@karger.com

www.karger.com

\section{Introduction}

Inflatable penile prosthesis (IPP) insertion in men with non-fibrotic corpora is usually a straightforward surgical undertaking. However, there are a significant number of men who have varying degrees of intracorporal fibrosis. Mild degrees of fibrosis are often seen in men with diabetes, or those who have been using intracorporal injection therapy. IPP insertion in these men is often only slightly more difficult than in those without fibrosis. However, extremely severe, obliterative intracorporal fibrosis is frequently seen in men who have a history of ischemic priapism, and in those who have had an infected IPP removed and not immediately replaced [1-3]. IPP cylinder insertion in these individuals can be quite difficult and occasionally impossible, and may require the use of specialized surgical instruments and narrow cylinders.

Review of the literature reveals that a wide variety of techniques have been developed to facilitate cylinder insertion into severely scarred corpora. These techniques include the use of corporal excavation, cavernotomes, urethrotomes, loop electroresection of fibrotic tissue, corporal counter-incisions, extended corporotomies, multiple corporal incisions with minimal scar tissue excision, use of narrow cylinders, and the use of synthetic, autologous, or xenografts for cylinder coverage [1-18]. A comprehensive review of these techniques has been recently published [19]. Each of these adjunctive techniques has advantages and limitations. To add to the literature on this challenging surgical situation, we present 


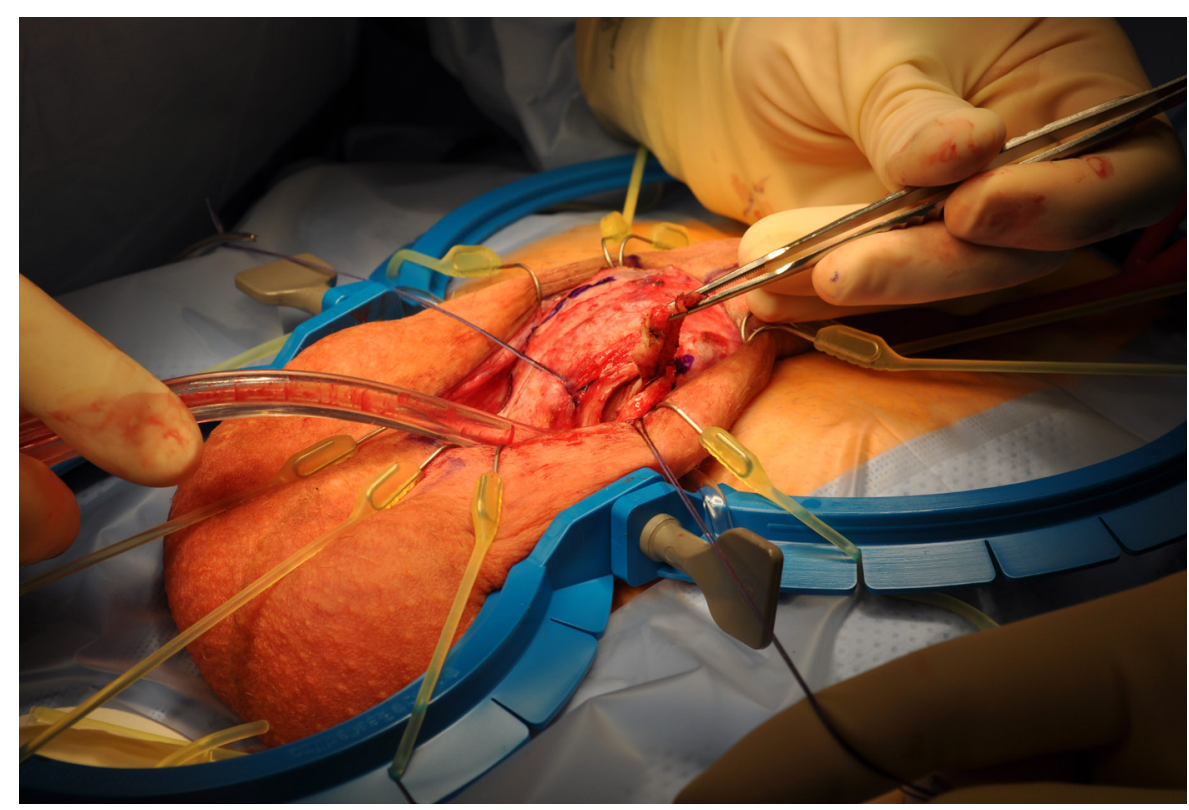

Fig. 1. Low coagulation current electrocautery has been used to resect the core of scar tissue immediately subjacent to the corporotomy.

a contemporary experience with IPP insertion into severely scarred corpora, and illustrate a sequence of surgical steps designed to facilitate a successful outcome.

\section{Patients and Methods}

All IPP procedures done by a high-volume prosthetic surgeon during a 5-year period were reviewed. Fourteen patients with severe corporal fibrosis underwent 15 attempted IPP insertion procedures, and are the subject of this review. These 14 patients developed severe intracorporal fibrosis either due to prior ischemic priapism, or due to an infected IPP that was removed and not immediately replaced. All patients received intravenous vancomycin and gentamicin immediately preoperatively, and all procedures were done on an outpatient basis. All patients had a Foley catheter and closed suction drain for $24 \mathrm{~h}$, and received 5 days of postoperative oral antibiotics. Data was obtained via retrospective medical records review; no institutional review board approval was required.

We have developed a sequence of surgical steps that seemed to facilitate a successful outcome. Cylinder insertion was uniformly approached via a long midline peno-scrotal incision. The corpora and urethra are defined using blunt and electrocautery dissection, and long corporotomy incisions are then marked. Holding sutures are placed, and a $2-3 \mathrm{~cm}$ corporotomy incision is made, revealing dense intracorporal fibrosis. Using low coagulation current, the electrocautery is used parallel to the inner edges of the tunica albuginea, allowing excision of a core of scar tissue immediately subjacent to the corporotomy (fig. 1). This step is important; it allows entrance into the corpus for subsequent cavernotome passage. Following this, sequential Uramix double-bladed cavernotomes (fig. 2) are then passed proximally and distally; the linear blades are able to cut a channel and sequentially enlarge it. Long Metzenbaum scissors can be used to dissect distally into the glans if needed. Sequential Carrion-Rossello cavernotomes are used thereafter, to further enlarge the corporal tunnels (fig. 3). Coloplast Titan ${ }^{\circledR}$ regular- or narrow-width cylinders were then inserted, depending on the size of the corporal tunnel that could be established. Pump and reservoir insertion are then carried out in standard fashion.

Operative success was defined as the ability to insert IPP cylinders (either regular or narrow-width), and to achieve an adequate erectile result, in the absence of any significant intraoperative complication (e.g. urethral injury). Patient satisfaction with the outcome is subjective, and was not assessed in this study. Retrospective review of medical records was carried out to obtain surgical details, final outcome, and length of follow-up.

\section{Results}

During a 5-year period, 14 patients with severe intracorporal fibrosis underwent 15 attempts at IPP insertion. Two patients had severe corporal fibrosis due to prior ischemic priapism; the remaining $12 \mathrm{had}$ undergone removal of an infected IPP without immediate replacement. Patient No. 3 could not be implanted due to corporal narrowing and obliteration. Patient \#6 underwent an initial 


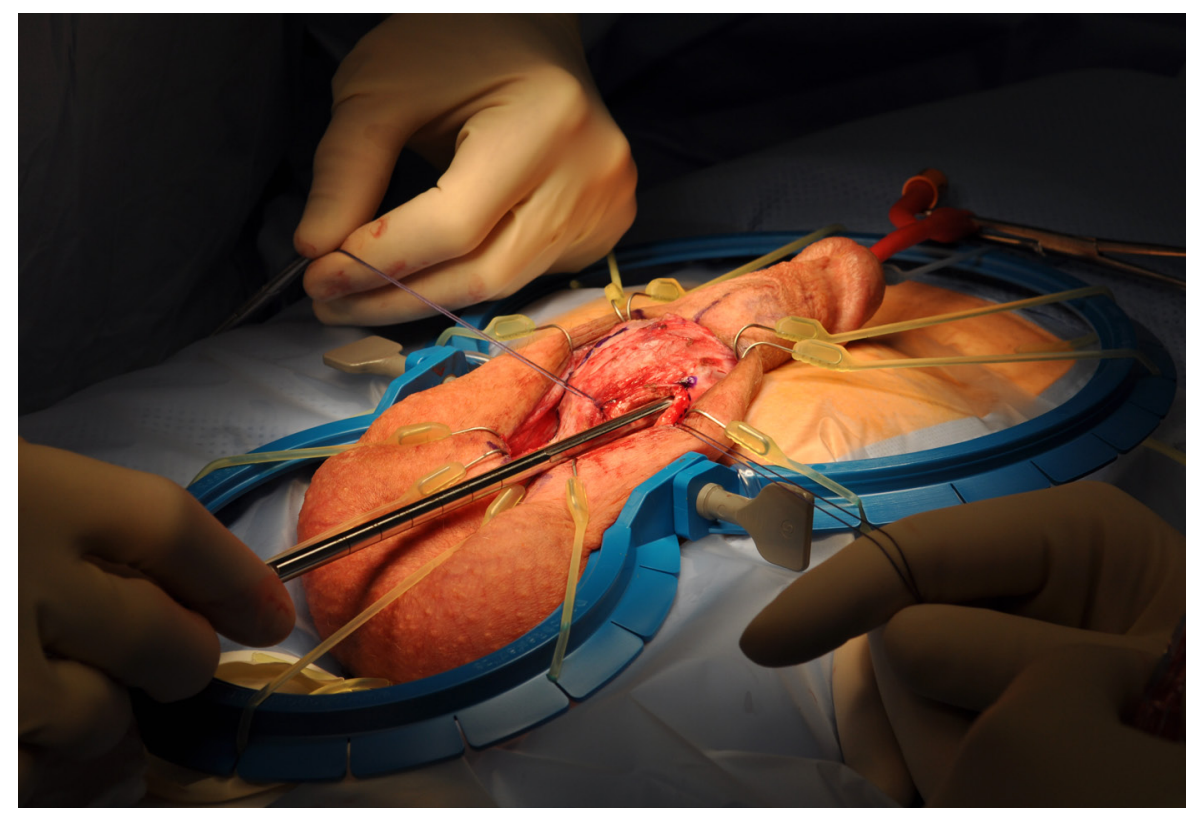

Fig. 2. A $6 \mathrm{~mm}$ Uramix double-bladed cavernotome is passed proximally and distally to establish an initial corporal channel. Sequentially larger Uramix cavernotomes are then inserted.

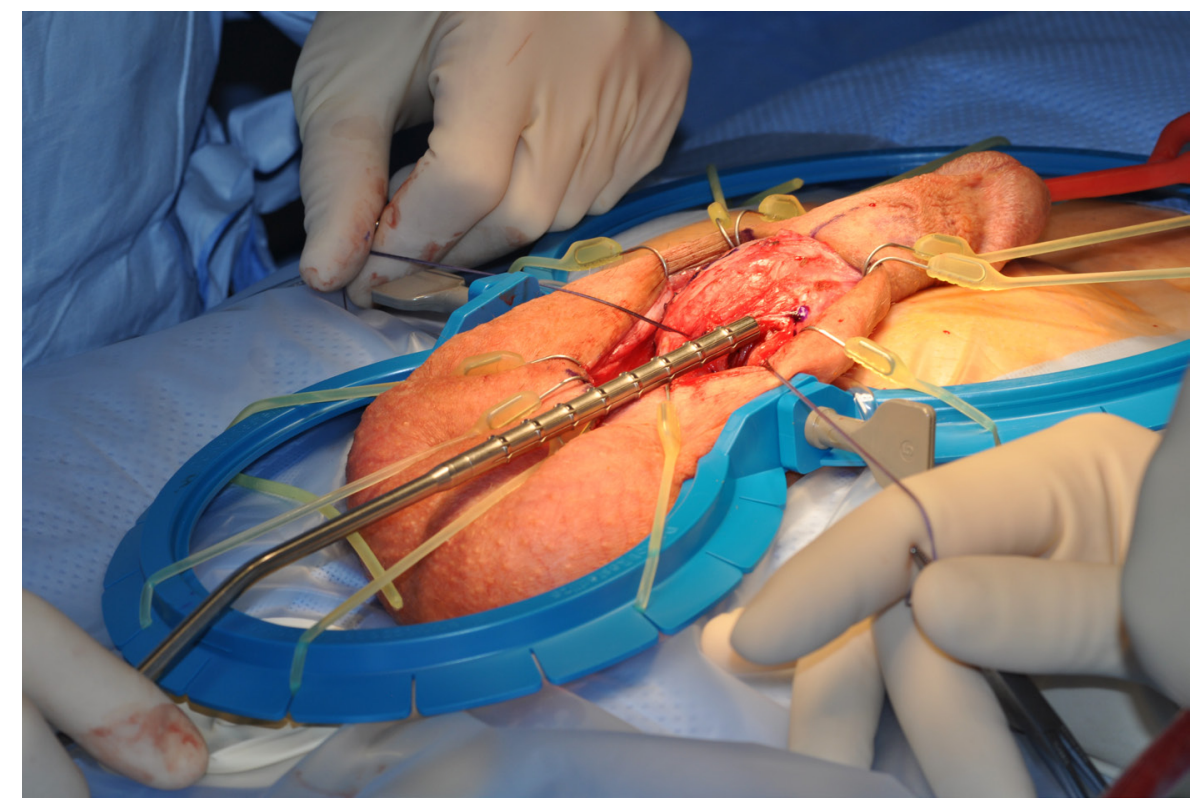

Fig. 3. Carrion-Rossello cavernotomes are then used to sequentially enlarge the corporal tunnels.

failed attempt at IPP insertion, but was allowed to heal and was successfully implanted with regular-sized cylinders roughly 10 months later. We attribute the success of this subsequent procedure to the use of Uramix double-bladed cavernotomes [7], which were not available at the time of his initial procedure. These cavernotomes 
Table 1. Corporal fibrosis patient data

\begin{tabular}{|c|c|c|c|c|c|c|c|c|}
\hline $\begin{array}{l}\text { Patient } \\
\text { No. }\end{array}$ & $\begin{array}{l}\text { Date of } \\
\text { surgery }\end{array}$ & Age & $\begin{array}{l}\text { Etiology of } \\
\text { fibrosis }\end{array}$ & $\begin{array}{l}\text { Left corporal } \\
\text { length }(\mathrm{cm})\end{array}$ & $\begin{array}{l}\text { Right corporal } \\
\text { length }(\mathrm{cm})\end{array}$ & IPP cylinder & $\begin{array}{l}\text { Follow-up } \\
\text { (months) }\end{array}$ & Outcome \\
\hline 1 & $6 / 28 / 10$ & 51 & priapism & 15 & 14 & narrow & 67 & healed \\
\hline 2 & $2 / 28 / 11$ & 54 & infection & 17 & 16 & narrow & 59 & healed \\
\hline 3 & $5 / 2 / 11$ & 61 & infection & $\mathrm{n} / \mathrm{a}$ & $\mathrm{n} / \mathrm{a}$ & $\mathrm{n} / \mathrm{a}$ & 57 & procedure aborted \\
\hline 4 & $10 / 31 / 11$ & 60 & infection & 17 & 17 & narrow & 51 & healed \\
\hline 5 & $4 / 8 / 13$ & 81 & infection & 19 & 19 & narrow & 34 & infected-explanted \\
\hline $6^{*}$ & $3 / 6 / 14$ & 59 & infection & $\mathrm{n} / \mathrm{a}$ & $\mathrm{n} / \mathrm{a}$ & $\mathrm{n} / \mathrm{a}$ & 23 & procedure aborted \\
\hline 7 & $3 / 7 / 14$ & 58 & infection & 23 & 23 & regular & 23 & healed \\
\hline 8 & $9 / 15 / 14$ & 67 & infection & 17 & 16 & narrow & 17 & healed \\
\hline 9 & $1 / 8 / 15$ & 72 & infection & 22 & 19 & narrow & 13 & infected-explanted \\
\hline $6^{*}$ & $1 / 15 / 15$ & 60 & infection & 25 & 25 & regular & 13 & healed \\
\hline 10 & $2 / 5 / 15$ & 47 & priapism & 18 & 19 & narrow & 12 & healed \\
\hline 11 & $2 / 9 / 15$ & 60 & infection & 21 & 21 & narrow & 12 & healed \\
\hline 12 & $2 / 23 / 15$ & 72 & infection & 21 & 21 & narrow & 11 & healed \\
\hline 13 & $6 / 11 / 15$ & 54 & infection & 15 & 15 & narrow & 8 & healed \\
\hline 14 & $9 / 3 / 15$ & 82 & infection & 18 & 18 & narrow & 5 & healed \\
\hline
\end{tabular}

*6 was not able to be implanted on $3 / 6 / 14$, but was successfully implanted $1 / 15 / 15$.

were able to cut an intracorporal channel, which could not be otherwise established. Overall, 13 of the 14 patients were successfully implanted; 11 required narrow cylinders, and 2 were able to accept regular-width cylinders. Two of these 14 patients (14\%) developed post-operative IPP infection and were explanted; neither underwent a salvage procedure, as both had undergone multiple prior IPP procedures that culminated in peri-prosthetic infection. Table 1 tabulates the results from this series of patients. There were no instances of corporal perforation, crossover, or urethral injury in this series.

\section{Discussion and Conclusions}

The development of severe intracorporal fibrosis is a virtual certainty in patients who have a history of prolonged ischemic priapism, or who have had an infected IPP removed and not immediately replaced via a salvage procedure. Some of these men will present for IPP insertion, which will be a challenge for even the most experienced prosthetic surgeon. A variety of surgical techniques have been described to address this situation. However, due to the small number of affected patients, and the small series' that have been previously published, the optimal surgical strategy cannot be definitively stated. The use of tunica albuginea-augmenting graft materials has fallen out of favor, because it is time-consuming and has a substantial risk of infection and need for subsequent revision.

Penile Prosthesis Insertion in Severe Intracorporal Fibrosis
In the present series, we were able to successfully implant 12 of the 14 patients. The 2 failed implantation procedures occurred prior to the availability of Uramix double-bladed cavernotomes. One of these patients declined any further surgery; the other patient returned and was successfully implanted at a second attempt, which was facilitated by the Uramix cavernotomes. In our hands, the Uramix double-bladed cavernotomes have been able to establish a corporal tunnel when other techniques have failed. Most (12/14) of our patients required narrow cylinders, but the remainder were able to receive regular-width cylinders. Although some patients are satisfied with narrow cylinders, Wilson et al. [20] reported the feasibility of subsequent cylinder upsizing after 1 year with narrow cylinders. Two of our 14 patients developed peri-prosthetic infection and required explantation; both were high-risk candidates with a prior history of multiple IPP procedures complicated by infection.

The specific surgical sequence that we prefer in the presence of severely scarred corpora involves a $2-3 \mathrm{~cm}$ corporotomy, electrocautery excision of intracorporal scar tissue subjacent to the corporotomy, initial establishment of corporal tunnels with sequential Uramix double-bladed cavernotomes, and then further enlargement of the tunnels with Carrion-Rossello cavernotomes [14], as illustrated in figs. 1-3. All of these techniques have been described previously; however, we have found that using them in this specific sequence has improved our ability to obtain a successful outcome. Regular or narrow cylinders can be used, depending on the final

Curr Urol 2016;10:92-96 
size of the corporal tunnels. We cannot state that this approach is the optimal method; we only contend that it has been helpful in our experience. Preoperative patient counseling and detailed informed consent is required in this patient population, since these procedures have historically had a significant risk of infection, urethral injury, inability to insert an implant, corporal perforation, unsatisfactory result, etc. Due to the surgical difficulties involved, we suggest that these procedures are best handled by experienced prosthetic surgeons. Limitations to our study include the small number of patients, and the effect of individual surgeon skill and experience on the final outcome. We herein describe our current approach to this challenging surgical situation, in the hope that it will "shorten the learning curve" for other urologists who are faced with these difficult implant situations.

\section{References}

1 Ghanem H, Ghazy S, El-Meliegy A: Corporeal counter incisions: a simplified approach to penile prosthesis implantation in fibrotic cases. Int J Impot Res 2000;12:153-156.

2 Montague DK, Angermeier KW: Corporeal excavation: new technique for penile prosthesis implantation in men with severe corporeal fibrosis. Urology 2006;67:1072-1075.

3 Lopes EJ, Kuwano AY, Guimaraes AN, Flores JP, Jacobino MA: Corporoplasty using bovine pericardium grafts in complex penile prosthesis implantation surgery. Int Braz $\mathbf{J}$ Urol 2009:35:49-53.

4 Park JK, Kim HJ, Kang MH, Jeong YB: Implantation of penile prosthesis in a patient with severe corporeal fibrosis induced by cavernosal injection therapy. Int J Impot Res 2002;14:545-546.

5 Pathak AS, Chang JH, Parekh AR, Aboseif SR: Use of rectus fascia graft for corporeal reconstruction during placement of penile implant. Urology 2005;65:1198-1201.

6 Palese MA, Burnett AL: Corporoplasty using pericardium allograft (tutoplast) with complex penile prosthesis surgery. Urology 2001; 58:1049-1052.
7 Mooreville M, Adrian S, Delk JR 2nd, Wilson SK: Implantation of inflatable penile prosthesis in patients with severe corporeal fibrosis: Introduction of a new penile cavernotome. J Urol 1999;162:2054-2057.

8 Rajpurkar A, Li H, Dhabuwala CB: Penile implant success in patients with corporal fibrosis using multiple incisions and minimal scar tissue excision. Urology 1999;54:145147.

9 Herschorn S, Ordorica RC: Penile prosthesis insertion with corporeal reconstruction with synthetic vacular graft material. J Urol 1995; 154:80-84

10 Fishman IJ: Corporeal reconstruction procedures for complicated penile implants. Urol Clin North Am 1989;16:73-90.

11 Fishman IJ: Complicated implantations of inflatable penile prostheses. Urol Clin North Am 1987;14:217-239.

12 George VK, Shah GS, Mills R, Dhabuwala $\mathrm{CB}$ : The management of extensive penile fibrosis: a new technique of "minimal scar-tissue excision”. Br J Urol 1996;77:282-284.

13 Knoll LD, Furlow WL: Corporeal reconstruction and prosthetic implantation for impotence associated with non-dilatable corporeal cavernosal fibrosis. Acta Urol Belg 1992;60: $15-25$.
14 Rossello Barbara M, Carrion H: Cavernotomy. Arch Esp Urol 1991;44:185-186.

15 Wilson SK: Tunnel technique for insertion of cylinders into scarred corporal bodies. http://www.vjpu-issm.info/index.php/videos?start=30

16 Shaeer O, Shaeer A: Corporoscopic excavation of the fibrosed corpora cavernosa for penile prosthesis implantation: optical corporotomy and trans-corporeal resection, Shaeer's technique. J Sex Med 2007;4:218-225.

17 Shaeer O: Implantation of penile prosthesis in cases of corporeal fibrosis: modified Shaeer's excavation technique. J Sex Med 2008;5:2470-2476.

18 Yafi FA, Sangkum P, McCaslin IR, Hellstrom WJ: Strategies for penile prosthesis placement in Peyronie's disease and corporal fibrosis. Curr Urol Rep 2015;16:21.

19 Trost L, Patil M, Kramer A: Critical appraisal and review of management strategies for severe fibrosis during penile implant surgery. J Sex Med 2015;12(suppl 7):439-447.

20 Wilson SK, Delk JR, Mulcahy JJ, Cleves M, Salem EA: Upsizing of inflatable penile implant cylinders in patients with corporeal fibrosis. J Sex Med 2006;3:736-742. 